UCRL-ID-132283

\title{
Accounting of Test Specimens for the Long-Term Corrosion Testing
}

\author{
Greg Gdowski
}

October 11,1995

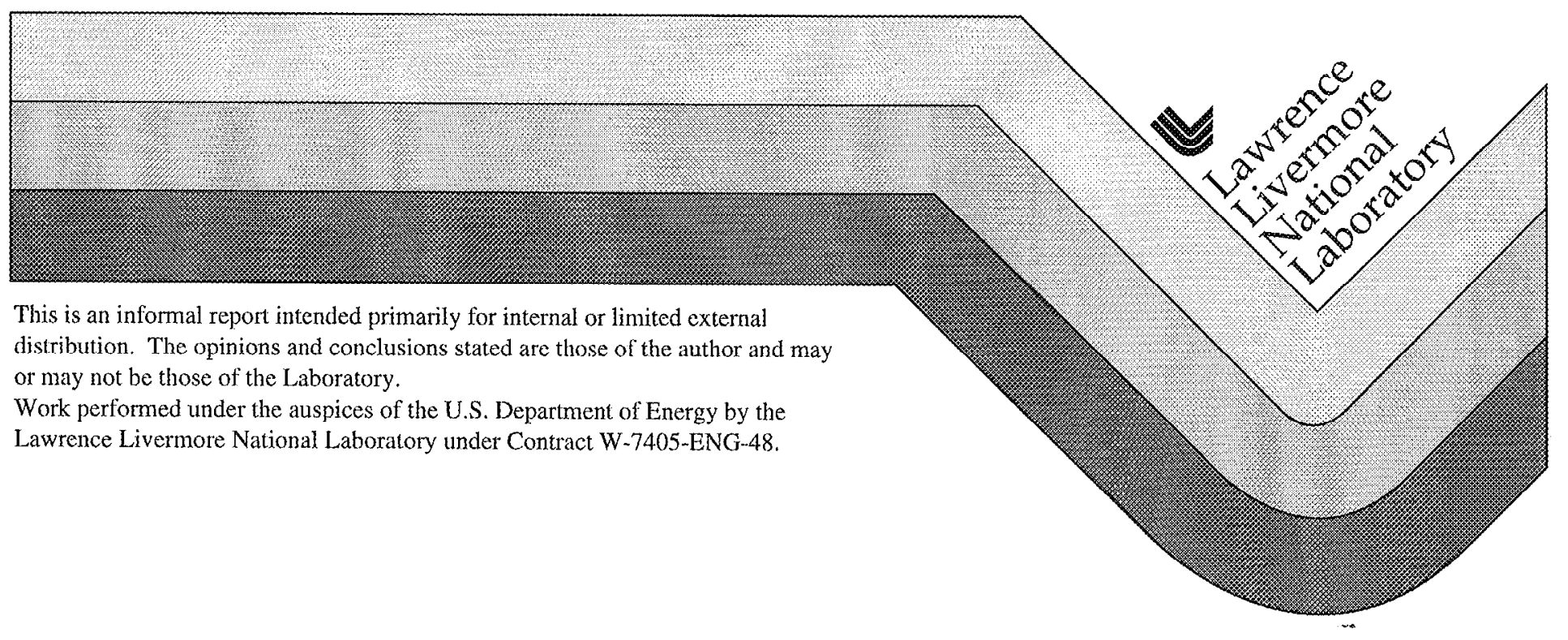




\section{DISCLAIMER}

This document was prepared as an account of work sponsored by an agency of the United States Government. Neither the United States Government nor the University of California nor any of their employees, makes any warranty, express or implied, or assumes any legal liability or responsibility for the accuracy, completeness, or usefulness of any information, apparatus, product, or process disclosed, or represents that its use would not infringe privately owned rights. Reference herein to any specific commercial product, process, or service by trade name, trademark, mamufacturer, or otherwise, does not necessarily constitute or imply its endorsement, recommendation, or favoring by the United States Government or the University of California. The views and opinions of authors expressed herein do not necessarily state or reflect those of the United States Government or the University of California, and shall not be used for advertising or product endorsement purposes.

This report has been reproduced directly from the best available copy.

Available to DOE and DOE contractors from the Office of Scientific and Technical Information

P.O. Box 62, Oak Ridge, TN 37831

Prices available from (423) 576-8401

Available to the public from the National Technical Information Service

U.S. Department of Commerce 5285 Port Royal Rd., Springfield, VA 22161 
YUCCA MOUNTAIN PROJECT

Technical Implementing Procedure

Accounting of Test Specimens for the Long-Term Corrosion Testing

G. Gdowski

Training Required: Yes No

Comments:

Training required for personnel performing work to this TIP.

REVISION HISTORY

Rev. No. CNNo. Effective Date Description of Revision/CN

0

$10 / 11 / 95$

Initial issue

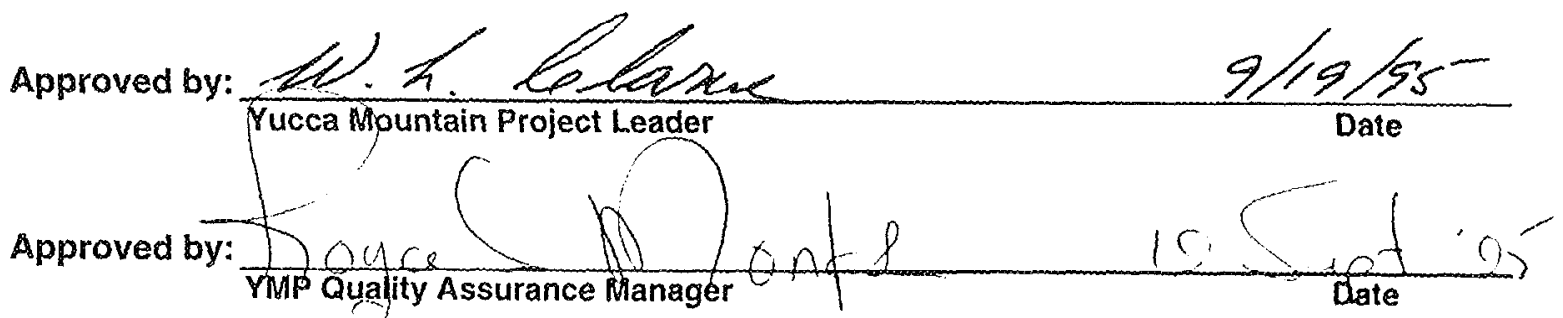

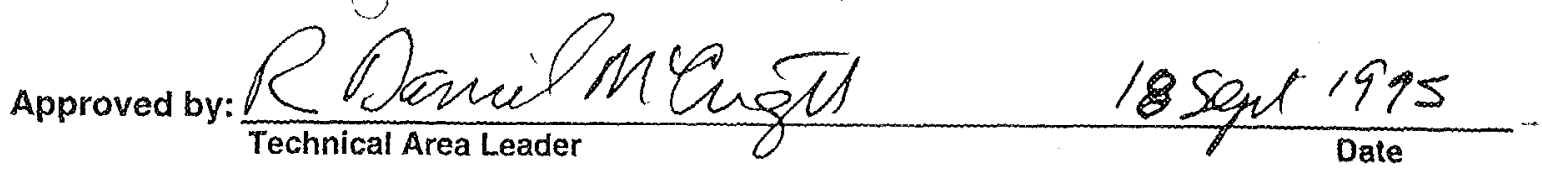




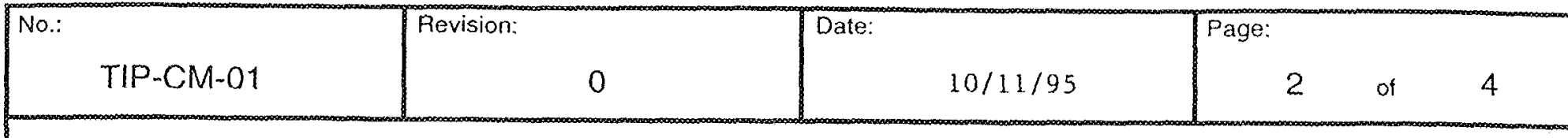

\subsection{PURPOSE}

The purpose of this TIP is to describe the procedures that will be employed for identification and control of test specimens for Activity E-20-50, “Long-Term Corrosion Studies". This TIP was written to comply with LLNL YMP procedure 033-YMP-QP 8.0, "Identification and Control of Items, Samples, and Data."

\subsection{SCOPE}

This TIP covers the identification and control of the long term corrosion test specimens in storage, testing, and during analysis.

The receipt, handling, and storage of the specimens during the activity is covered by the TIP-CM-02, "Receiving, Handling, and Storage of Specimens for Long-Term Corrosion Testing," which satisfies the requirements of LLNL YMP procedure 033-YMP-QP 13.0, "Handling, Storage, and Shipping."

\subsection{RESPONSIBILITIES}

The Principal Investigator (PI) or designee is responsible for:

- the conduct of the activities and methods described in this procedure,

- maintaining scientific notebooks.

The Task Leader (TL) is responsible for:

- $\quad$ assuring that the requirements of this procedure are implemented.

The Technical Area Leader (TAL) is responsible for:

- verifying that this procedure meets the objectives of the applicable Scientific Investigation Plans and other project planning documents such as Activity Plans.

The XMP Quality Assurance Manager is responsible for:

- monitoring the implementation and for assuring the continuing effectiveness of the applicable controls.

\subsection{PROCEDURES}

4.1 Identification

\subsubsection{Initial identification}

Test specimens are fabricated by a qualified supplier. Each specimen will have a unique identification number that will be placed on the specimen during fabrication. The placement of the identification number must not influence the corrosion processes to be characterized. The 


\begin{tabular}{|c|c|c|c|c|c|}
\hline No: & Revision: & Date: & Page: & & \\
\hline TIP-CM-01 & 0 & $10 / 11 / 95$ & 3 & of & 4 \\
\hline
\end{tabular}

specimen identification numbers and their required location on the specimens are specified in the specimen procurement documentation.

\subsubsection{In test vessel}

Because the corrosion testing might obscure the identification numbers on the test specimens, the position of each specimen on the specimen rack will be documented in the scientific notebook before insertion of the rack into a test vessel. The identification will also include the rack number and the vessel number. Test vessels will have unique identification numbers.

\subsubsection{After testing}

If, as a result of the testing, the identification number of a test specimen has been obscured by corrosion, a label with the specimen ID number will be attached to the specimen storage packaging. The specimen will be in the packaging when it is not being analyzed. Storage packaging is described in TIP-CM-02, "Receiving, Handling, and Storage of Specimens for Long-Term Corrosion Testing".

\subsection{Tracking}

Specimen tracking information is documented in scientific notebooks which contain the following tracking information as a minimum: date of specimen receipt from vendor, specimen identification numbers, specimen storage location, specimen start and finish dates of testing, specimen location in test vessels, dates and custodian of specimens during post-test analysis, and the results of the post-test analysis.

In the event that a specimen is subdivided during post-test analysis, each of the pieces shall be assigned a unique identification number, preferably an extension on the identification number of the parent specimen.

\subsection{Activity completion}

At the completion of the activity, the specimens will be stored in their protective packaging for at least one year or until it has been decided by the TAL that storage is no longer warranted.

\subsection{TRAINING}

Personnel responsible for handling of the specimens for Activity E-20-50 must be trained to this TIP. 


\begin{tabular}{|c|c|c|c|c|c|}
\hline No:: & Revision: & Date: & Page: & & \\
\hline TIP-CM-01 & 0 & $10 / 11 / 95$ & 4 & of & 4 \\
\hline
\end{tabular}

\subsection{APPLICABLE SPECIMENS}

This TIP applies to those specimens that were procured for Activity E-20 50, "Long-Term Corrosion Studies."

\subsection{QUALITY SURVEILLANCES}

Periodic surveillances to verify that the requirements of the TIP are being implemented shall be performed.

\subsection{QUALITY ASSURANCE RECORDS}

The following are retained as Quality Assurance records:

- scientific notebooks

\subsection{ASSOCIATED ACTIVITY AND TIPS}

This TIP is written in association with Activity E-20-50, "Long-Term Corrosion Studies." A companion TIP for identification and control of the specimens is TIP-CM-02, "Receiving, Handling, and Storage of Specimens for Long-Term Corrosion Testing." 